\title{
Responses of root growth of Alhagi sparsifolia Shap. (Fabaceae) to different simulated groundwater depths in the southern fringe of the Taklimakan Desert, China
}

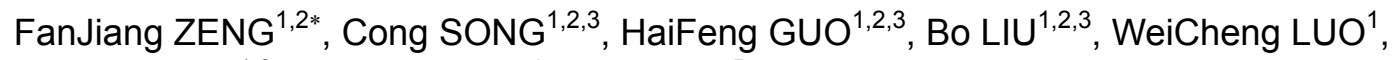 \\ DongWei GUI ${ }^{1,2}$, Stefan ARNDT ${ }^{4}$, DaLi GUO ${ }^{5}$ \\ ${ }^{1}$ State Key Laboratory of Desert and Oasis Ecology, Xinjiang Institute of Ecology and Geography, Chinese Academy of Sciences , \\ Urumqi 830011, China; \\ ${ }^{2}$ Cele National Station of Observation and Research for Desert-Grassland Ecosystem, Cele 848300, China; \\ ${ }^{3}$ University of Chinese Academy of Sciences, Beijing 100049, China; \\ ${ }^{4}$ School of Forest and Ecosystem Science, University of Melbourne, Victoria 3363, Australia; \\ ${ }^{5}$ Institute of Geographic Sciences and Natural Resources Research, Chinese Academy of Sciences, Beijing 100101, China
}

\begin{abstract}
Alhagi sparsifolia Shap. (Fabaceae) is a spiny, perennial herb. The species grows in the salinized, arid regions in North China. This study investigated the response characteristics of the root growth and the distribution of one-year-old $A$. sparsifolia seedlings to different groundwater depths in controlled plots. The ecological adaptability of the root systems of $A$. sparsifolia seedlings was examined using the artificial digging method. Results showed that: (1) A. sparsifolia seedlings adapted to an increase in groundwater depth mainly through increasing the penetration depth and growth rate of vertical roots. The vertical roots grew rapidly when soil moisture content reached $3 \%-9 \%$, but slowly when soil moisture content was $13 \%-20 \%$. The vertical roots stopped growing when soil moisture content reached $30 \%$ (the critical soil moisture point). (2) The morphological plasticity of roots is an important strategy used by $A$. sparsifolia seedlings to obtain water and adapt to dry soil conditions. When the groundwater table was shallow, horizontal roots quickly expanded and tillering increased in order to compete for light resources, whereas when the groundwater table was deeper, vertical roots developed quickly to exploit space in the deeper soil layers. (3) The decrease in groundwater depth was probably responsible for the root distribution in the shallow soil layers. Root biomass and surface area both decreased with soil depth. One strategy of $A$. sparsifolia seedlings in dealing with the increase in groundwater depth is to increase root biomass in the deep soil layers. The relationship between the root growth/distribution of $A$. sparsifolia and the depth of groundwater table can be used as guidance for harvesting $A$. sparsifolia biomass and managing water resources for forage grasses. It is also of ecological significance as it reveals how desert plants adapt to arid environments.
\end{abstract}

Keywords: Alhagi sparsifolia Shap.; simulated groundwater depth; root system growth and distribution; ecological adaptability; root morphological plasticity

Citation: FanJiang ZENG, Cong SONG, HaiFeng GUO, Bo LIU, WeiCheng LUO, DongWei GUI, Stefan ARNDT, DaLi GUO. 2013. Responses of root growth of Alhagi sparsifolia Shap. (Fabaceae) to different simulated groundwater depths in the southern fringe of the Taklimakan Desert, China Journal of Arid Land, 5(2): 220-232.

The relationship between plant and soil moisture is an important topic of research in plant ecology in arid regions. The root system is the most important organ in plants for the absorption of water and nutrients. In an ecological system where soil moisture is limited, the availability of water and nutrients to plants largely depends on the environmental conditions, as well as the size, morphology and competitiveness of the root

*Corresponding author: FanJiang ZENG (E-mail: zengfj@ms.xjb.ac.cn) Received 2012-08-13; revised 2012-10-14; accepted 2012-11-02

(C) Xinjiang Institute of Ecology and Geography, Chinese Academy of Sciences, Science Press and Springer-Verlag Berlin Heidelberg 2013 
systems (Zhang et al., 2012). The Taklimakan Desert is one of the most arid areas in the world, where the average annual precipitation is less than $50 \mathrm{~mm}$. The survival of natural plants in such an extremely arid environment is a result of evolutionary adaptation to the extreme environment (Schenk, 2005; Gong et al., 2012). In the arid ecosystem of the Taklimakan Desert, moisture is the major limiting factor and, in the study area, it is rare for moisture to be available to plants in soil layers that are above the edge of groundwater capillarity (Li et al., 2010; Ma et al., 2011). Several dominant perennial species at the fringe of the oasis need to be in contact with groundwater if they are to survive, whereas the roots of seedlings must reach the limits of water capillary action if their root systems are not to be threatened by soil drought. The increase in groundwater depth significantly affects the growth and distribution of Populus deltoids (Rood et al., 2000) and the water potential changes in Salix gooddingii and P. fremontii (Horton et al., 2003). These indicate that the depth of the groundwater table has a long-term effect on the ecological balance and vegetation diversity (Nilsson et al., 1997).

Alhagi spp. are perennial, leguminous and lignified herbs growing in deserts and semi-deserts. Ball and Robbins (1933) described several Alhagi spp. in Russia and mainly focused on the morphology of thorns and leaves. During the same period, Graham (1941) recognized that Alhagi spp. played an important role in preventing soil erosion, suggesting that they should be protected and utilized as much as possible. A study on the morning water potential and daily changes in water potential of Alhagi sp. during two consecutive vegetation growth cycles showed that flood did not affect the water conditions of Alhagi sp., but neither did water deficiency occur in Alhagi sp. A. sparsifolia has been shown to have a relatively high osmotic potential compared with several other desert plants (e.g. Tamarix chinensis, P. diversifolia and Calligonum mongolicum) in the same study area and showed no water stress during the growing period (Li et al., 2002). In addition, $A$. sparsifolia has a relatively high transpiration rate, which becomes more obvious during the daily changes in stomatal conductance. Clearly, $A$. sparsifolia can access a sufficient water supply for survival. In the study area, the rainfall is negligible, with no flooding events on the sample plot and no available capillary water in the soil, so the survival and growth of $A$. sparsifolia must largely depend on groundwater resources (Thomas et al., 2000). Research on stable carbon/oxygen isotopes in the leaf organics of $A$. sparsifolia and associated salt-tolerance characteristics in plants has confirmed that groundwater is the available water source for $A$. sparsifolia and that $A$. sparsifolia can endure a certain degree of salinity (Arndt et al., 2004a). Previous research has shown that $A$. sparsifolia can obtain a continuous and sufficient water supply, showing no signs of water stress during the growing period and producing good growth. On the southern fringe of the Taklimakan Desert, $A$. sparsifolia can not only fix nitrogen (N) from the atmosphere, but also obtain substantial $\mathrm{N}$ supplies from groundwater, thereby obtaining a sufficient nutrient supply for growth and survival (Arndt et al., 2004b). Some researchers have demonstrated that the growth status of $A$. sparsifolia is related to the depth of the groundwater table (Agzhigitova et al., 1995; Khafagi, 1995). Based on observations and experiments for several years, we found that the root systems of A. sparsifolia adults could reach to $7-16 \mathrm{~m}$ in deep soil layers to exploit the groundwater in natural environment and that the root systems of one-year-old A. sparsifolia could reach to $2.8 \mathrm{~m}$ in deep soil layers to utilize the soil water under controlled conditions (unpublished data). The plant's main response to environmental changes, particularly changes in soil moisture content, is through the root system. Under dry conditions, the root systems show a certain degree of plasticity in their growth (Reader et al., 1993), and changes in root growth, density, surface area and distribution patterns are more sensitive to change than soil nutrients and other physiological parameters of root systems (Jastrow and Miller, 1993; George et al., 1997). However, groundwater is one of the main water sources for natural vegetation in arid areas, and changes in the depth of the groundwater table have a profound effect on the growth and morphological distribution of plant roots.

This study was conducted under poor soil conditions in an extremely arid area. The responses of deep-rooted $A$. sparsifolia seedlings to a water supply controlled by groundwater depth were investigated. 
The hypotheses were: (1) The exploitation depth of $A$. sparsifolia seedling roots would gradually increase with an increase in groundwater depth and the growth rate of their vertical roots would be positively correlated with groundwater depth. (2) Previous studies have shown that the responses of A. sparsifolia seedling root systems to a good soil environment are mainly manifested as an increase in the development of horizontal roots with over-ground suckering to compete for light resources, whereas the responses to arid soil environments are mainly manifested as an increase in the development of vertical roots in order to exploit resources in deeper soil layers. (3) A decrease in groundwater depth may cause the root systems to be distributed in shallow soil layers and root biomass and surface area to decrease with increasing soil depth.

\section{Materials and methods}

\subsection{Study area}

This study was conducted at the Cele National Station of Observation and Research for Desert-Grassland Ecosystem, Xinjiang Institute of Ecology and Geography, Chinese Academy of Sciences. The Cele Station is located on the leading edge of the Cele Oasis $\left(36^{\circ} 51^{\prime} 30^{\prime \prime} \mathrm{N}, 80^{\circ} 44^{\prime} 28^{\prime \prime} \mathrm{E}\right)$, and has a typical inland desert climate and is in a warm temperate zone. The annual average temperature is $11.9^{\circ} \mathrm{C}$ and the monthly average temperature is $-11.7^{\circ} \mathrm{C}$ in January and $25.2^{\circ} \mathrm{C}$ in July. The extreme maximum temperature is $41.9^{\circ} \mathrm{C}$ and the extreme minimum temperature is $-23.9^{\circ} \mathrm{C}$. The precipitation is relatively low and the rain mainly occurs between May and July. The average annual precipitation in the oasis plain is $35.1 \mathrm{~mm}$, with an average annual evaporation potential of up to $2,595.3 \mathrm{~mm}$. The groundwater depth is approximately $16 \mathrm{~m}$ within the oasis area and $7 \mathrm{~m}$ at the leading edge of the oasis, and shows an obvious seasonal change trend. The natural vegetation in the area is mainly $A$. sparsifolia. The soil, groundwater and local climate at the experimental plot were close to natural conditions. The average soil moisture and nutrient contents between the soil depths of 0 and $350 \mathrm{~cm}$ under natural conditions were as follows: soil moisture content (MC) of
$3.30 \%$, available nitrogen (AN) of $10.79 \mathrm{mg} / \mathrm{kg}$, available phosphorous (AP) of $2.06 \mathrm{mg} / \mathrm{kg}$, available potassium (AK) of $80.97 \mathrm{mg} / \mathrm{kg}$, total nitrogen $(\mathrm{TN})$ of $0.02 \mathrm{~g} / \mathrm{kg}$, total phosphorous (TP) of $0.50 \mathrm{~g} / \mathrm{kg}$, total potassium (TK) of $2.14 \mathrm{~g} / \mathrm{kg}$, and organic matter (OM) of $0.26 \mathrm{~g} / \mathrm{kg}$ (Fig. 1).

Our field experiment went on for 1 year. The experimental plot $\left(72 \mathrm{~m}^{2}\right)$ consisted of eight independent subplots $\left(9-\mathrm{m}^{2}\right.$ total cultivation area; $\left.3 \mathrm{~m} \times 3 \mathrm{~m}\right)$ where the depth of the groundwater table could be controlled. The specific construction structure of the controlled groundwater table plots is as follows: the experimental plot was found in cement pools $(3 \mathrm{~m}$ long, $3 \mathrm{~m}$ wide and $3 \mathrm{~m}$ deep), which were constructed to simulate the groundwater table at $250 \mathrm{~cm}$. At the $250-\mathrm{cm}$ soil depth, a water-resisting soil layer consisting of pebbles and wire netting prevented further upward movement of the water and made a water space. The water space was supported by pillars. An intake pipe was designed to allow water to flow into the water space. To create the other three treatments (groundwater tables of 100, 150 and $200 \mathrm{~cm}$ ), the height of the water space was raised to the height of the required water table for that plot. All other features of the tank (plot) making up each plot were the same. Each tank was planted with 16 A. sparsifolia seedlings (Fig. 2). The eight cultivation subplots were identical in structure, with the groundwater table maintained at one of the four different depths: 100, 150, 200 and $250 \mathrm{~cm}$.

The experimental subplots were constructed between 20 March and 15 April, 2007 and were then sown with $A$. sparsifolia seeds. Prior to planting, the groundwater was continuously supplied, allowing the recovery of the soil to a naturally compact state. Then, an initial flood irrigation (15 cm deep) was performed in the cultivation area to ensure that the naturally dry layer in the top $30 \mathrm{~cm}$ of the soil was wet enough for seed germination. A. sparsifolia seeds were subjected to carbonization and a seedcoat removal treatment (sulfuric acid for $5 \mathrm{~min}$ ) and then washed with water. Thinning was carried out on 3 May, with plants being thinned to intervals of $50 \mathrm{~cm}$. Three days after the seeds were sown; watering cans were used to water the seedlings three times a day (morning, noon and evening) to ensure seedling survival. During this period, protective measures were taken, such as shading 


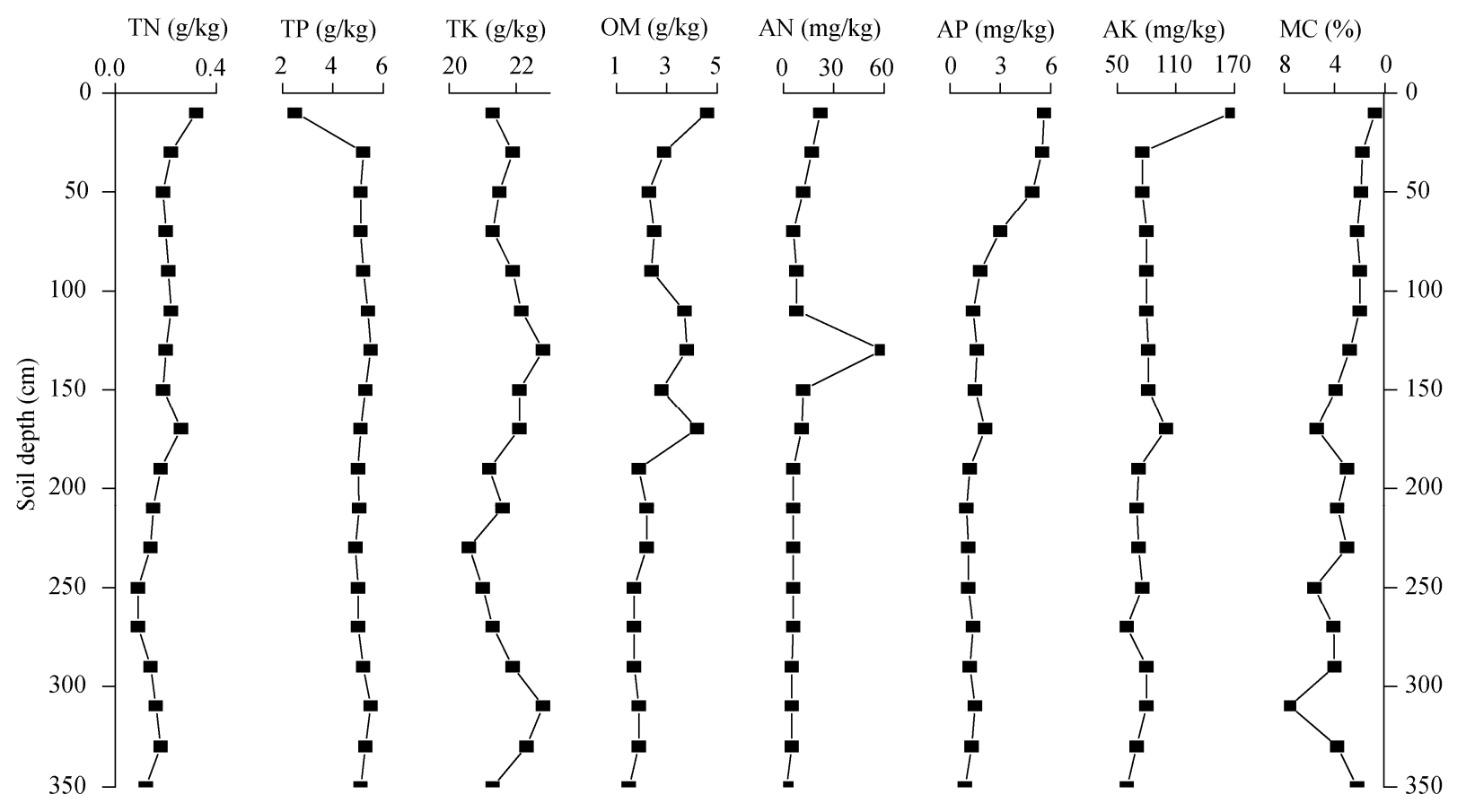

Fig. 1 Vertical distribution of soil nutrients and moisture contents from 0 to $350 \mathrm{~cm}$ in the sample plot. TN, total nitrogen; TK, total phosphorus; OM, organic matter; AN, available nitrogen; AP, available phosphorus; AK, available potassium; MC, moisture content. Values are mean \pm SE, $n=3$.

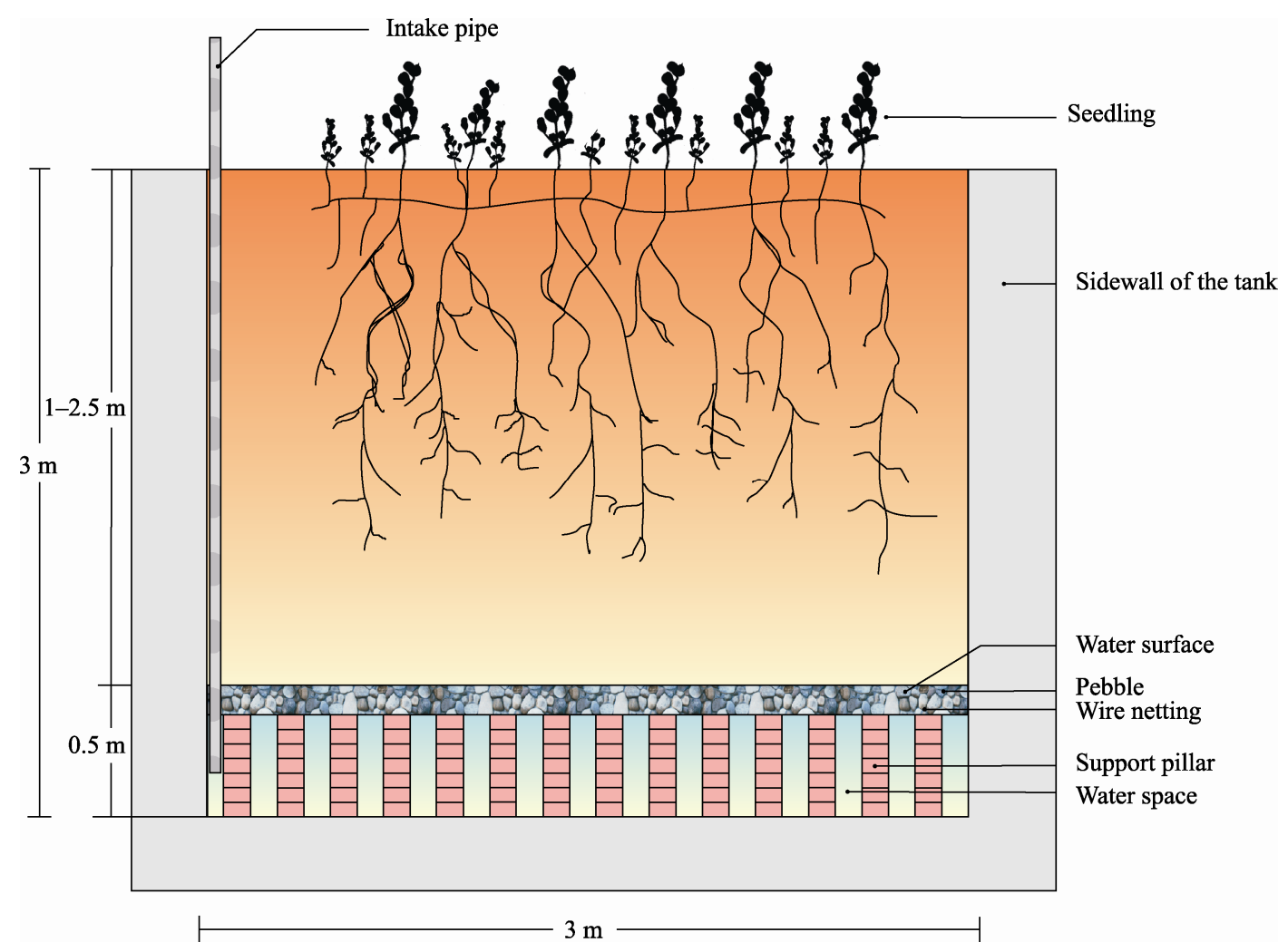

Fig. 2 The structure diagram of the controlled groundwater table plots 
and preventing damage from birds and animals. Further thinning of the seedlings was conducted 45 days after sowing, leaving one or two seedlings per hole.

\subsection{Sampling and analytical methods}

1.2.1 Determination of soil moisture content

The soil moisture content was determined by the gravimetric method using a boring auger and aluminum specimen boxes.

\subsubsection{Root growth investigation}

A survey of root growth was carried out in July, August, September and October, respectively. For each treatment, eight replicate samples of $A$. sparsifolia roots were collected at the four controlled groundwater depths $(n=32)$. Of these, one out of the eight replicate samples was used to construct the root morphology diagram. In total, 16 root configuration diagrams were drawn.

During the root survey, eight plants, which showed good growth, were randomly selected as the standard samples for each treatment. The ground diameters, plant heights and crown widths were determined for the standard samples and a layered mining survey was performed on the root systems of the selected plants. The plant root was taken as the center and the soil mining was undertaken at a $20-\mathrm{cm}$ interval. During the mining process, all the roots at each layer were collected, using root tracking and sieving methods, and then sorted according to root diameters $(\leq 1 \mathrm{~mm}, 1-3$ $\mathrm{mm}$, and $\geq 3 \mathrm{~mm}$ ). The roots were rinsed with water and the diameter was measured at three different positions using a vernier gauge. The length of thick roots was measured using a steel measuring tape and the length of the fine roots was determined via a mass-to-length conversion. (i.e. the mass of a fine root was converted to a length of a specific diameter according to the mass of a $10-\mathrm{cm}$ root fragment of the same diameter). The roots were sorted and classified, packed in marked envelopes and transported to the laboratory, together with the above-ground parts. The samples were oven-dried at $80^{\circ} \mathrm{C}$ to a constant weight. The dried plant samples of above-ground parts and roots were weighed separately. The results were used to calculate the dry weight of the above- and belowground biomasses and the layered root surface areas.

1.2.3 Description of root morphology
The root system was dug out using an artificial trench-mining method. During the mining process, efforts were made to not disturb the spatial positions of root systems. The cut-open view of the root morphology was drawn onto coordinate papers $(1: 20)$, in situ, using fixation, coordinate labeling, and digital photography.

\subsection{Data processing}

\subsubsection{Calculation of soil moisture content}

Soil moisture content was calculated using the following equation:

$$
\theta_{m}=\frac{W_{1}-W_{2}}{W_{2}} \times 100 \% .
$$

Where $\theta_{m}$ is the soil moisture content (\%), $W_{1}$ is the wet soil mass (g), and $W_{2}$ is the dry soil mass (g).

\subsubsection{Calculation of vertical root growth rate}

The growth rates of vertical roots were calculated using the following equation:

$$
R_{V R G}=\frac{R D T M-R D L M}{G D} .
$$

Where $R_{V R G}$ is the growth rate of vertical roots $(\mathrm{cm} / \mathrm{d})$, $R D_{T M}$ is the depth of the vertical roots (cm) in a specific month, $R D_{L M}$ is the depth of the vertical roots $(\mathrm{cm})$ in the previous month, and $G D$ refers to the days of growth.

\subsubsection{Calculation of root surface area}

The root surface areas were calculated using the following equation:

$$
A=\frac{\sum \pi \times L \times D^{2}}{4} .
$$

Given that each root is approximately cylindrical, $A$ refers to the root surface area $\left(\mathrm{cm}^{2}\right), L$ refers to the root length $(\mathrm{cm})$, and $D$ refers to diameter $(\mathrm{cm})$.

The statistical analysis was performed using EXCEL 2010 and SPSS 18.0. The root distribution diagrams were drawn using Photoshop CS4 and Illustrator 10.0 .

\section{Results and analysis}

\subsection{Vertical root growth of $A$. sparsifolia at dif- ferent ground water depths}

To some extent, the plant height to rooting depth ratio can reflect the relationship between plant growth and the external environment. The plant height to rooting 
depth ratio of $A$. sparsifolia decreased with the increase in simulated groundwater depths during the growing season. This may be an adaptation strategy that adjusts its allocation proportion to root growth when drought stress is encountered. Except the roots corresponding to a groundwater depth of $150 \mathrm{~cm}$ was less than that of at a groundwater depth of $200 \mathrm{~cm}$ in September (Fig. 3).

The root length of $A$. sparsifolia seedlings also gradually increased with the increase in groundwater depth (Fig. 4). During the growing season, the absolute root length of vertical roots at the different simulated groundwater depths were as follows: $250 \mathrm{~cm}>$ $200 \mathrm{~cm}>150 \mathrm{~cm}>100 \mathrm{~cm}$. This indicated that the increase in groundwater depth promoted the growth of vertical roots.



Fig. 3 The plant height to rooting depth ratio of $A$. sparsifolia juveniles subjected to different groundwater table depth treatments. The different columns indicate the different groundwater table depths. Each value is mean $\pm S E, n=8$.

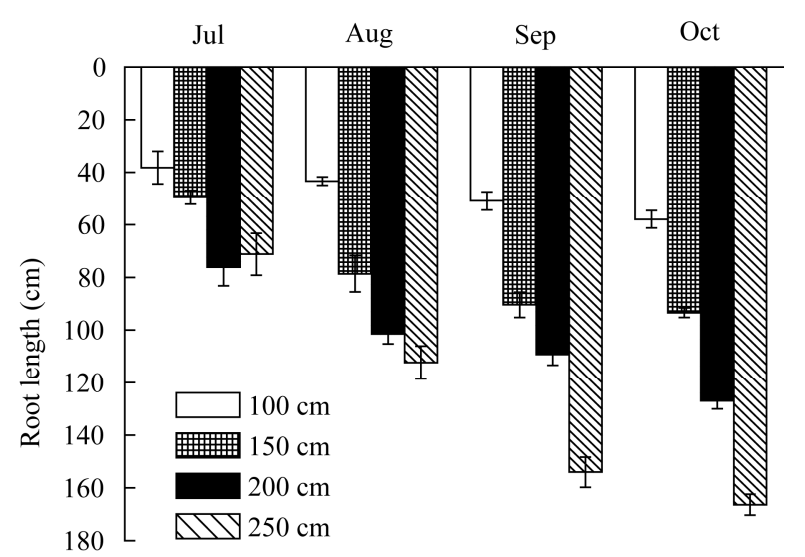

Fig. 4 Root lengths of $A$. sparsifolia juveniles subjected to different groundwater table depth treatments. The root lengths of juveniles were measured between July and October. Each value is the mean $\pm S E$ of eight measurements.

During the 155-d growing period, the average growth rates of the vertical roots of $A$. sparsifolia seedlings at the four groundwater table depths (100, 150,200 and $250 \mathrm{~cm}$ ) were $0.37,0.60,0.82$ and 1.07 $\mathrm{cm} / \mathrm{d}$, respectively (Fig. 5). This showed that the vertical root growth rate of $A$. sparsifolia seedlings was positively correlated with the groundwater depth. However, there were variations in the vertical root growth rate. The maximum root growth rate at the groundwater depths of 100, 150 and $200 \mathrm{~cm}$ occurred in the first two months after planting (early May-late July), whereas the maximum growth rate at the groundwater depth of $250 \mathrm{~cm}$ and with the drought treatment appeared near the end of the growing season (late September). The monthly average growth speed of vertical roots reached $1.44 \mathrm{~cm} / \mathrm{d}$ at a groundwater depth of $250 \mathrm{~cm}$. The root growth rate fell for all treatments at the end of the growing season (late October).

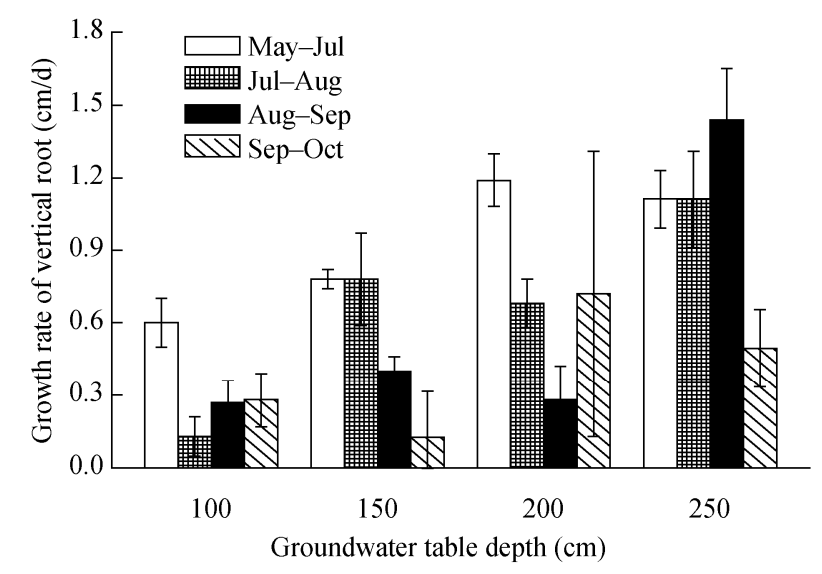

Fig. 5 The rooting growth rates of $A$. sparsifolia juveniles at different groundwater table depths. The rate of vertical root growth from May to July=(the root length on 6 July)/64; the rate of vertical root growth from July to August=(the root length on 19 August-the root length on 6 July)/45; the rate of vertical root growth from August to September=(the root length on $17 \mathrm{Sep}$ tember-the root length on 19 August)/30; the rate of vertical root growth from September to October=(the root length on 12 October-the root length on 17 September)/36. Mean \pm SE, $n=8$.

\subsection{Root morphological characteristics of $A$. spar- sifolia at different groundwater depths}

The root morphological characters at each groundwater depth showed that the root systems of $A$. sparsifolia seedlings could be divided into two groups (Fig. 6). The roots showed various morphological characters at different groundwater depths, which suggested that $A$. sparsifolia seedling roots could adapt to changes in groundwater depth. 

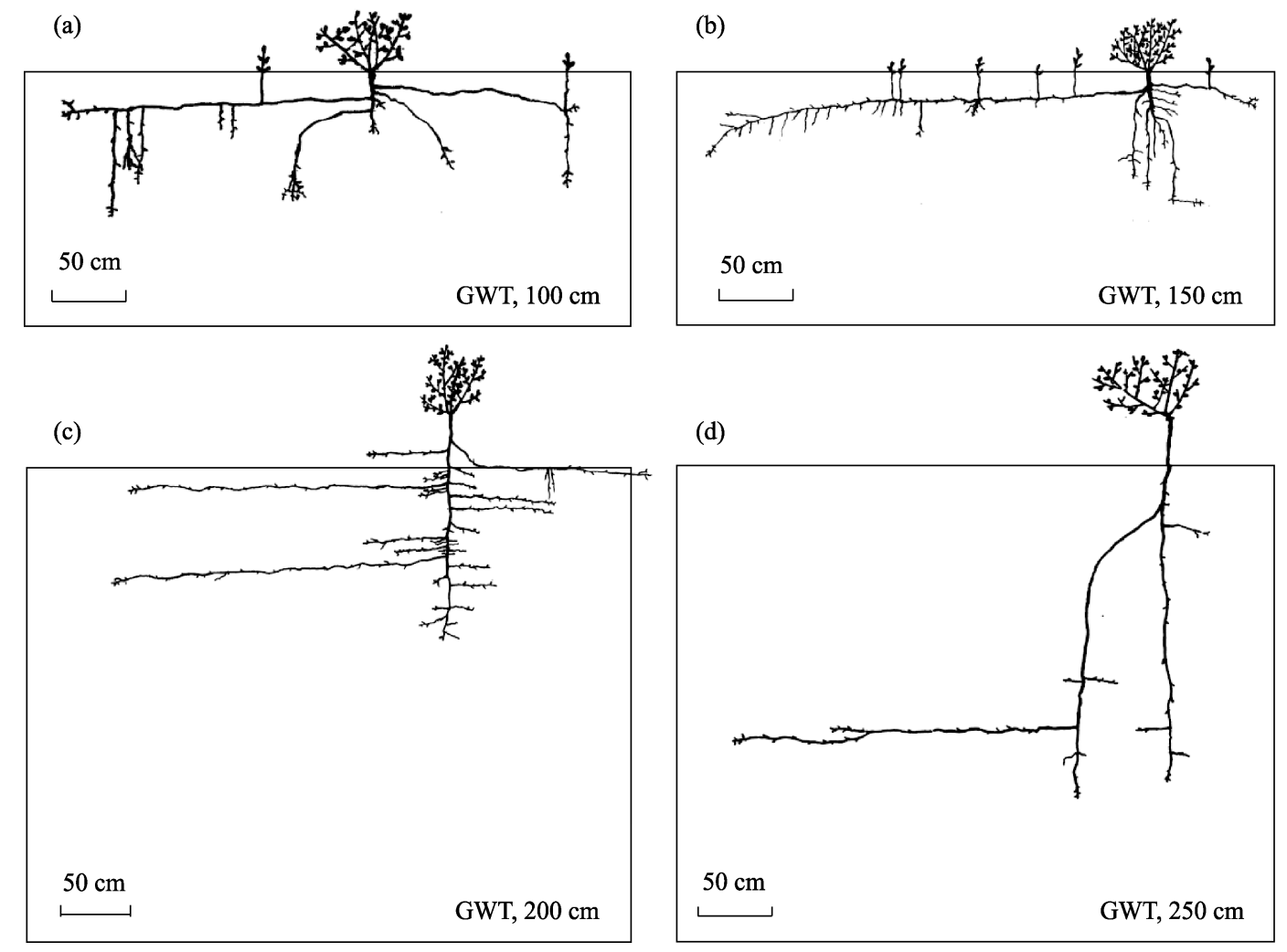

Fig. 6 The root architecture of $A$. sparsifolia juveniles under different groundwater table treatments. GWT is groundwater table.

Further comparison of the root morphological characteristics associated with different groundwater depths showed that: (1) The horizontal root systems were well developed when the groundwater depth was 100,150 , and $200 \mathrm{~cm}$ and had a substantially longer length than the vertical roots. All treatments produced tillering and suckering, with the exception of the roots when the groundwater depth was $200 \mathrm{~cm}$. (2) The roots of $A$. sparsifolia seedlings were vertical when the groundwater depth was $250 \mathrm{~cm}$. (3) Horizontal roots only appeared when the groundwater table was $200 \mathrm{~cm}$ or above.

The results also showed that: (1) The roots of $A$. sparsifolia seedlings at groundwater depths of 100 and $150 \mathrm{~cm}$ showed tillering three months after planting (late August), whereas roots at groundwater depths of 200 and $250 \mathrm{~cm}$ showed no tillering during the four surveys. (2) Root tillering almost entirely occurred in the top 20-40 cm soil layer. (3) The growth of $A$. sparsifolia seedlings was greatest when the groundwater depth was $150 \mathrm{~cm}$ and there was a significant increase in suckering, whereas, at the depth of $100 \mathrm{~cm}$, there was substantial evaporation and soil salinization, which resulted in pronounced leaf withering.

It should be noted that the roots were not disturbed as far as possible during excavation. If the root system was not entirely in the same plane, then some horizontal roots and the vertical roots were taken into account when constructing the root architecture. Finally, the results should show a special two-dimensional surface of the root system.

\subsection{Root distribution patterns of $A$. sparsifolia seedlings at different groundwater depths}

In this study, the root distribution pattern refers to the distribution of root biomass and the surface area of $A$. sparsifolia seedlings in the soil profile (Fig. 7). A decrease in groundwater depth led to a concentration of root biomass and surface area in the upper soil layers. The root biomass and surface area of the seedlings when the groundwater depth was at $250 \mathrm{~cm}$ were evenly distributed in the top $120 \mathrm{~cm}$ of the soil, and then the root surface area suddenly increased at $100-140 \mathrm{~cm}$. The roots of $A$. sparsifolia seedlings associated with the groundwater depth of $200 \mathrm{~cm}$ were mainly distributed in the top $100 \mathrm{~cm}$ of the soil. Root biomass was greatest at the soil depth between 
20 and $40 \mathrm{~cm}$, whereas the root surface area was greatest at the depth between 80 and $100 \mathrm{~cm}$. The roots of $A$. sparsifolia seedlings associated with the groundwater depth of $150 \mathrm{~cm}$ were mainly distributed in the top $60 \mathrm{~cm}$ of the soil, with the greatest root biomass being at the depth of $0-20 \mathrm{~cm}$, and the greatest root surface area was found at the depth of 40-60

(a) Root biomass (g)

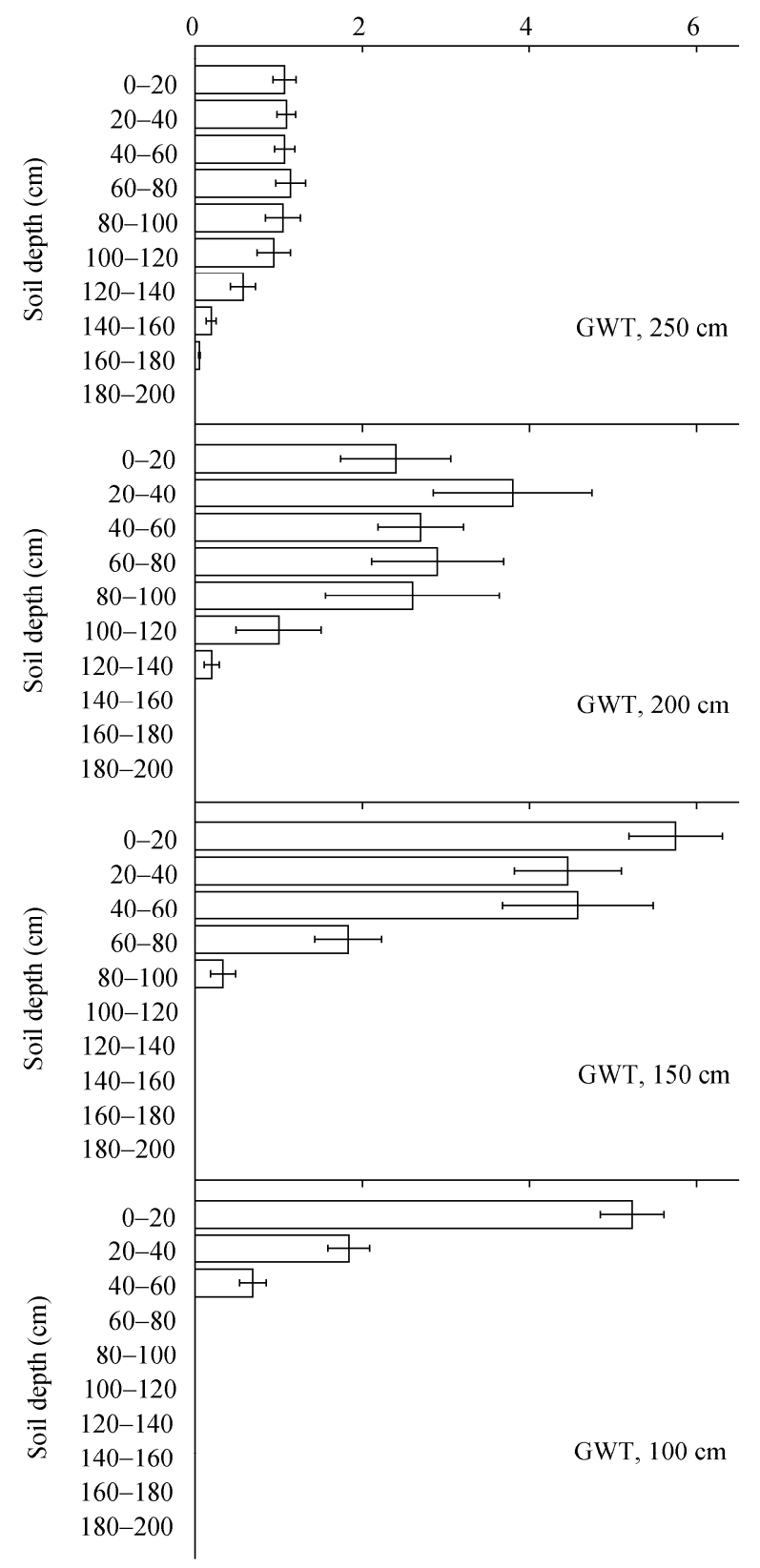

$\mathrm{cm}$. Both root length and root surface area at the groundwater depth of $150 \mathrm{~cm}$ were substantially higher than found in the other three groundwater depth treatments. The root biomass and root surface area of A. sparsifolia seedlings associated with the groundwater depth of $100 \mathrm{~cm}$ were concentrated in the top 20 $\mathrm{cm}$ of the soil. (b) Root surface area $\left(\mathrm{cm}^{2}\right)$

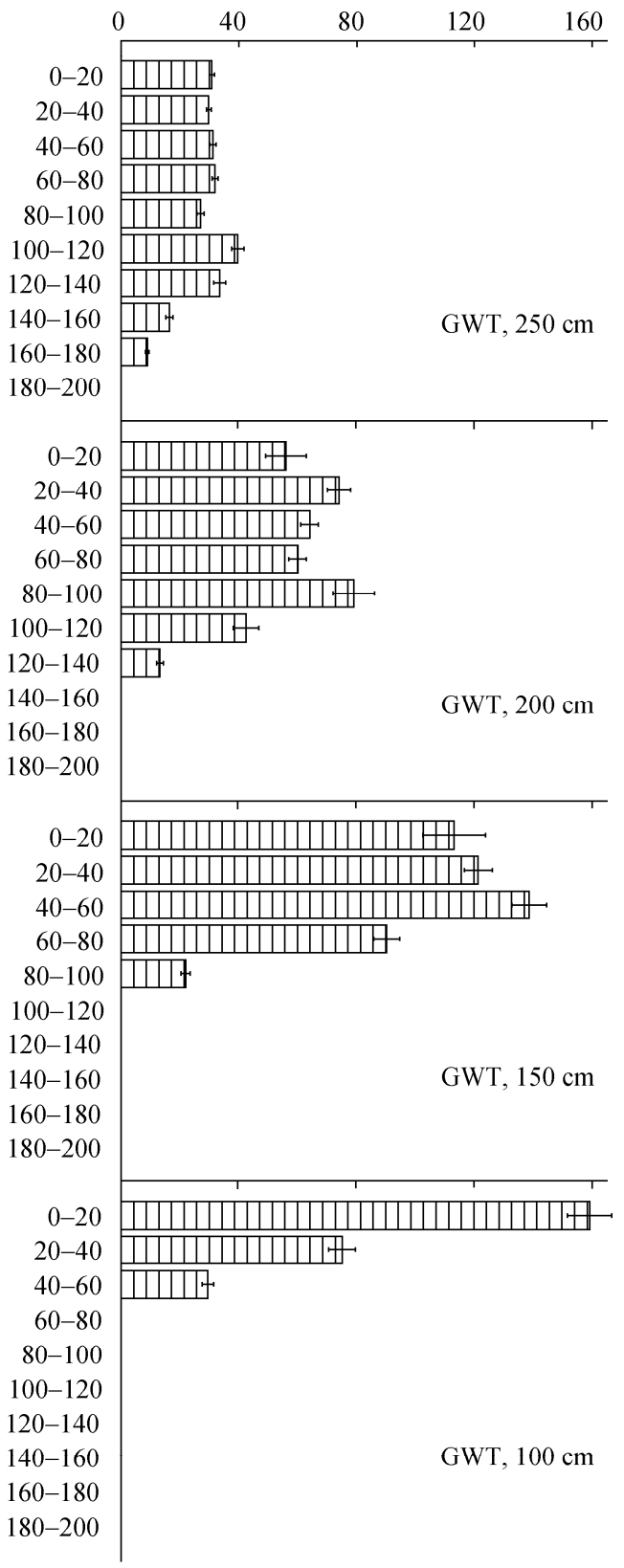

Fig. 7 Root biomass (a) and root surface area (b) of $A$. sparsifolia seedlings for different groundwater table treatments in October. Values are mean \pm SE, $n=8$. 


\section{Discussion}

\subsection{The relationship between vertical root growth and groundwater depth}

Soil moisture is the key factor controlling the vertical distribution of plant roots and, therefore, plant adsorption capability. Zhou and Shangguan (2007) studied the fine root density and biomass of Pinus tabulaeformis Carr. on the Loess Plateau and suggested that soil moisture had a greater effect on root distribution than soil inorganic nitrogen in arid and semi-arid areas. Schenk and Jackson (2002) considered that with increasing drought stress, the relative root length of herbaceous plants increased to a certain degree and the absolute root length declined relative to the growth of aboveground parts. This study found that an increase in groundwater depth led to an increase in the vertical root length (including both relative and absolute root lengths) and the growth rate of $A$. sparsifolia seedlings. This, to some extent, confirmed the results of previous studies that vertical root growth increased under the drought conditions (Sharp and Davies, 1985; Pallardy and Rhoads, 1993). Schulze et al. (1996) also suggested that when drought occurred during the growing period of desert plants, the plants could actively grow downwards to seek water. Furthermore, under arid conditions, it took only approximately 150 days for $A$. sparsifolia seedlings to geminate and grow roots to a depth of $260 \mathrm{~cm}$. This study showed that the vertical root growth rate of $A$. sparsifolia reached $3.14 \mathrm{~cm} / \mathrm{d}$ in September, further demonstrating that the vertical roots grew faster in the growing season when temperatures were optimal (Drennan and Nobel, 1996). The increase in vertical root growth can significantly increase moisture absorption (de Kroon and Visser, 2003). In addition, the increase during the summer has been shown to effectively absorb moisture from deep soil (Canadell and Zedler, 1995). This helps A. sparsifolia seedlings to survive and grow in arid periods by utilizing groundwater resources (Lloret et al., 1999).

It is very important to study the response characteristics of root growth of $A$. sparsifolia seedlings to different groundwater depths, because it will provide a valuable theoretical basis for proper water resource management in the process of the restoration of $A$. sparsifolia in extreme arid areas. From the root growth observed in the study, the vertical root systems of $A$. sparsifolia seedlings could go down to deeper soil layers under higher groundwater depths (200 and $250 \mathrm{~cm}$ ) than under relatively shallow groundwater depths $(100$ and $150 \mathrm{~cm})$ in the early growing season. Generally speaking, it promotes the vertical growth of the root systems of the species seedlings when the soil moisture is limited in the early growing period, which is of significance for the proper utilization of water resources during the restoration of desert plants.

At the beginning of the study, there was a concern that the roots of $A$. sparsifolia seedlings would penetrate the groundwater table at shallow depths. However, the results showed that the root systems did not always grow downwards. After three months of growth, the $A$. sparsifolia seedlings had almost stopped the downward growth of vertical roots in the treatments with groundwater depths of 100 and 150 $\mathrm{cm}$, and substantial horizontal root growth and aboveground tillering were observed. Further research might be into why the roots did not always grow downwards or even penetrate the groundwater table.

In order to further understand the quantitative relationship between soil moisture content and vertical root growth, the relationship between the root growth of $A$. sparsifolia seedlings and the soil moisture contents under different groundwater depths was analyzed (Fig. 8).

The results showed that the average root length of $A$. sparsifolia seedlings was $166 \mathrm{~cm}$ at the groundwater depth of $250 \mathrm{~cm}$, corresponding to a soil moisture content of $32.8 \%$; at the groundwater depth of $200 \mathrm{~cm}$, the average root length was $124 \mathrm{~cm}$, corresponding to a soil moisture content of $29.9 \%$; and at the groundwater depth of $100 \mathrm{~cm}$, the average root length was 51 $\mathrm{cm}$, corresponding to a soil moisture content of $30.8 \%$. These results indicated that the soil moisture content of $30 \%$ was the critical value for the vertical root growth of $A$. sparsifolia seedlings (the saturated soil moisture content of the tested soils was 33.3\%). From the results mentioned above, the vertical root systems could continue to go down deeper in the soil layers unless the saturated soil moisture content reached the critical value of $30 \%$. This could be related to changes 


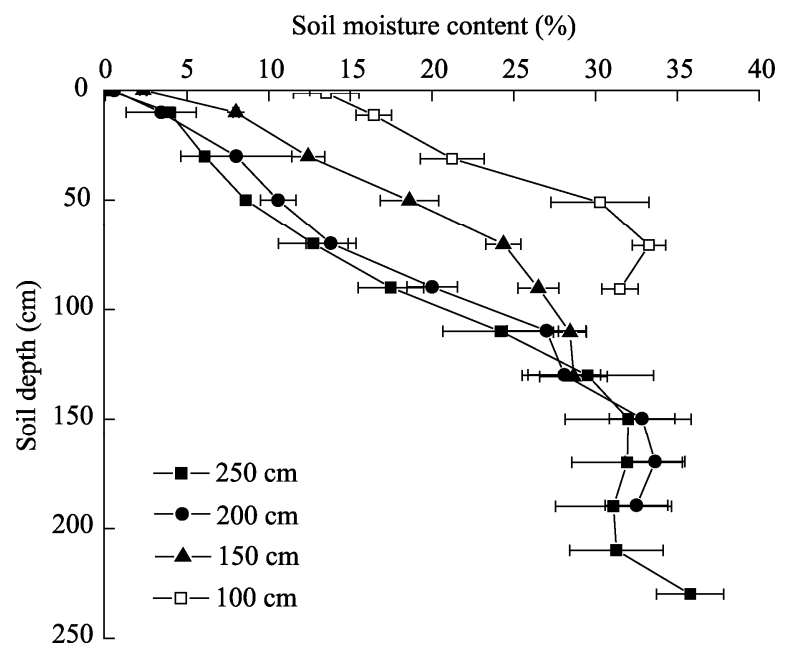

Fig. 8 Moisture content in the vertical soil profiles for different groundwater table treatments. The soil moisture content was measured at the end of the growing season and the four curves represent the different groundwater table depths $(250,200,150$ and $100 \mathrm{~cm}$ ). Values are mean \pm SE, $n=3$.

in root respiration, as the saturation of the soil would limit root respiration due to a lack of oxygen. If the moisture was completely absorbed by the plants, the roots may enter a dormant stage and only continue to grow downward when further water became available (Schulze et al., 1996).

\subsection{Relationship between root morphology and groundwater depth}

Soil moisture had a positive effect on the root morphology of A. sparsifolia seedlings. Good soil moisture conditions resulted in well-developed horizontal roots, obvious suckering and vertical roots that had a shallower length. However, dry conditions resulted in substantial downward root growth and the spatial range of the root distribution gradually expanded with the increase in soil moisture. This revealed that the high root morphological plasticity of $A$. sparsifolia seedlings varied with moisture conditions. Roots are the most important organ for plant growth. Plants respond to the environment, especially moisture content, mainly through the root system, which shows clear plasticity during the adaptation of a plant to its environment (Grime et al., 1991). The phenotypic plasticity of a plant refers either to the expression of different phenotypes by the same plant genotype due to its adaption to different environments (Bradshaw, 1965) or to the different phenotypic abilities of individual organisms subjected to different environmental impacts at various growth stages (Pigliucci, 2005). Phenotypic plasticity has been considered to be one of the most important response characteristics of an organism to environmental conditions or stimuli, as well as being the phenotypic foundation of biological adaptation (Huey et al., 2000). Plasticity has been thought to be a flexible strategy by which plants adapt to the local environment. Growth plasticity is an important feature of plants that enables them to adapt to heterogeneous environments in terms of moisture and nutrients (Via et al., 1995). In natural environments, moisture usually exists in soils in a heterogeneous form. In order to continuously obtain resources and adapt to local environments, plants may seek resources using active foraging strategies (Kembel and Cahill Jr, 2005). In response to soil conditions at shallow groundwater depths, A. sparsifolia developed horizontal roots and increased tillering in order to compete for light resources; whereas in response to soil conditions at deep groundwater depths, A. sparsifolia developed vertical roots and expanded its root biomass in the deeper soil layers. This observation is important when considering the ecological restoration of $A$. sparsifolia. The results of this study suggested that a reduction in moisture supply during the early growth stages would promote the downward growth of vertical roots, while an increase in moisture supply during later growth stages would promote the clonal propagation and tillering of $A$. sparsifolia seedlings. This would improve the survival and propagation of $A$. sparsifolia in extremely arid environments and demonstrated that root morphological plasticity is an important strategy used by $A$. sparsifolia seedlings to obtain moisture and adapt to arid environments.

\subsection{Relationship between root distribution and groundwater depth}

Research regarding plant root distribution can be dated back to 1727 when Hales first investigated crops (Jackson et al., 1996). In many non-forest ecosystems, over $80 \%$ of the total plant biomass is found in the soil (Caldwell and Richards, 1986). The wide distribution of root systems, such as fine roots, in soils enables a larger volume of soil to be exploited by plant roots or allows the exploitation of the same volume of soil to 
be enhanced (Joslin et al, 2000). The root distribution pattern of plants depends on the horizontal and vertical distribution of water and root morphological plasticity. The spatial distributions of belowground biomass are mainly reflected by the different vertical distributions of belowground biomass, i.e. the root biomass in a spatial gradient is uneven. The research into belowground biomass in typical grassland in the middle of Missouri, USA showed that $48 \%-60 \%$ of the root biomass was distributed below the top 2 feet (ca. $60 \mathrm{~cm}$ ) in the soil profile (Dahlman and Kucera, 1965). In this study, the vertical distribution of root biomass for $A$. sparsifolia when subjected to different groundwater depths was as follows: it gradually decreased with an increase in soil depth, which is consistent with the universal law concerning the vertical distribution of plant roots. In general, plant root biomass decreases with increasing soil depth (Schenk, 2005). The results from this study showed that the vertical distribution of root biomass for $A$. sparsifolia seedlings was negatively correlated with soil depth. Schulze et al. (1996) also showed that root biomass decreased with soil depth for all vegetation types. The root surface area has a close relationship with soil moisture absorption (Jackson et al., 1997). In tundra areas, the aboveground biomass per unit volume largely depends on root surface area rather than a good environment (Shaver and Billings, 1975). To some extent, this means that plants can offset the stress of an extreme environment by increasing the root surface area. However, this was not confirmed by this study. Instead, this study obtained the optimal range of water absorption by the root surface area of $A$. sparsifolia seedlings at different groundwater depths. The maximum root surface area associated with the four groundwater depth treatments $(250,200,150$ and 100 $\mathrm{cm})$ occurred in the 100-140, 80-100, 40-60 and 0-20 cm soil layers, respectively. The associated soil moisture contents were between $13 \%$ and $20 \%$, which demonstrated the strong absorption ability of $A$. sparsifolia roots within this soil moisture range.

\section{Conclusions}

Vertical root growth of $A$. sparsifolia seedlings was most significantly affected by soil moisture. A. sparsifolia seedlings mainly adapted to drought by in- creasing the vertical root length and growth rate. The vertical roots grew fastest and were most sensitive to soil moisture within the range of 3\%-9\% soil moisture contents, but showed slow downward growth when the soil moisture contents were between $13 \%$ and $20 \%$. The vertical roots stopped growing when soil moisture content exceeded $30 \%$, at which point soil moisture became the limiting factor on root growth.

A. sparsifolia seedlings mainly had horizontal and vertical roots. Root morphological plasticity is an important strategy for improving the uptake of soil moisture and adapting to arid environments. When the groundwater depth was less than $200 \mathrm{~cm}$, horizontal roots predominated and the plants showed increased tillering in order to compete for light resources. When the groundwater depth was deeper than $250 \mathrm{~cm}$, vertical roots predominated in order to exploit the deep soil layers for moisture.

A decrease in groundwater depth caused the plant roots to be distributed in the shallow soil layers. The root biomass and surface area of $A$. sparsifolia decreased with soil depth, and increasing root biomass in the deeper soil layers has been shown to be a strategy utilized by $A$. sparsifolia seedlings in order to deal with arid soil conditions. When exploiting and utilizing pasture grasses, a groundwater depth of $150 \mathrm{~cm}$ was found to be most favorable for belowground root biomass accumulation and a depth of $200 \mathrm{~cm}$ was found to be most favorable in promoting belowground root biomass accumulation. The findings of this study can be used to increase the biomass yield of $A$. sparsifolia and improve the management of water resources for a number of different forage grasses.

\section{Acknowledgements}

This work was supported by the Knowledge Innovation Program of the Chinese Academy of Sciences (KZCX2-EW-316), the National Natural Science Foundation of China (31070477, 30870471) and the West Light Foundation of the Chinese Academy of Sciences (XBBS201105). We are grateful to the anonymous reviewers for reviewing this manuscript.

\section{References}

Agzhigitova N I, Allanazarova U, Kapustina L A, et al. 1995. Transformation of desert pasture vegetation under effect of anthropogenic pressure. Problems of Desert Development, 3: 
$62-65$.

Arndt S K, Arampatsis C, Foetzki A, et al. 2004a. Contrasting patterns of leaf solute accumulation and salt adaptation in four phreatophytic desert plants in a hyperarid desert with saline groundwater. Journal of Arid Environments, 59(2): 259-270.

Arndt S K, Kahmen A, Arampatsis C, et al. 2004b. Nitrogen fixation and metabolism by groundwater-dependent perennial plants in a hyperarid desert. Oecologia, 141(3): 385-394.

Ball W S, Robbins W W. 1933. Camelthorn, Alhagi camelorum fish. Monthly Bulletin of the California State Department of Agriculture, 22: $258-260$.

Bradshaw A D. 1965. Evolutionary significance of phenotypic plasticity in plants. In: Caspari E W. Advances in Genetics. London: Academic Press Inc. (London) Ltd., Berkeley Square House, 13: $115-155$.

Caldwell M M, Richards J H. 1986. Competing root systems: morphology and models of absorption. In: Givnish T J. On the Economy of Plant Form and Function. Cambridge: Cambridge University Press, 251-271.

Canadell J, Zedler P H. 1995. Underground structures of woody plants in Mediterranean ecosystems of Australia, California and Chile. In: Arroyo M T K, Zedler P H, Fox M D. Ecology and Biogeography of Mediterranean Ecosystems in Chile, California, and Australia. New York: Springer-Verlag, 177-210.

Dahlman R C, Kucera C L. 1965. Root productivity and turnover in native prairie. Ecology, 46: 84-89.

de Kroon H, Visser E J W. 2003. Root Ecology. Heidelberg: Springe Berlin Heidelberg, 150-191.

Drennan P M, Nobel P S. 1996. Temperature influences on root growth for Encelia farinosa (Asteraceae), Pleuraphis rigida (Poaceae), and Agave deserti (Agavaceae) under current and doubled $\mathrm{CO}_{2}$ concentrations. American Journal of Botany, 83: 133-139.

George E, Seith B, Schaeffer C, et al. 1997. Responses of Picea, Pinus and Pseudotsuga roots to heterogeneous nutrient distribution in soil. Tree Physiology, 17(1): 39-45.

Gong Y M, Hu Y K, Fang F, et al. 2012. Carbon storage and vertical distribution in three shrubland communities in Gurbantünggüt Desert, Uygur Autonomous Region of Xinjiang, Northwest China. Chinese Geographical Science, 22(5): 541-549.

Graham E H. 1941. Legumes for Erosion Control and Wildlife. Washington: U. S. Department of Agriculture.

Grime J P, Campbell B D, Mackey J M I. 1991. Root plasticity, nitrogen capture and competitive ability. In: Atkinson D. Plant Root Growth: An Ecological Perspective. Oxford: Blackwell Scientific Press, 381-397.

Horton J L, Hart S C, Kolb T E. 2003. Physiological condition and water source use of Sonoran Desert riparian trees at the Bill Williams River, Arizona, USA. Isotopes in Environmental and
Health Studies, 39(1): 69-82.

Huey R B, Gilchrist G W, Carlson M L, et al. 2000. Rapid evolution of a geographic cline in size in an introduced fly. Science, 287(5451): 308-309.

Jackson R B, Canadell J, Ehleringer J R, et al. 1996. A global analysis of root distributions for terrestrial biomes. Oecologia, 108(3): 389-411.

Jackson R B, Mooney H A, Schulze E D. 1997. A global budget for fine root biomass, surface area, and nutrient contents. Proceedings of the National Academy of Sciences of the United States of America, 94(14): 7362-7366.

Jastrow J D, Miller R M. 1993. Neighbor influences on root morphology and mycorrhizal fungus colonization in tallgrass prairie plants. Ecology, 74(2): 561-569.

Joslin J D, Wolfe M H, Hanson P J. 2000. Effects of altered water regimes on forest root systems. New Phytologist, 147(1): 117-129.

Kembel S W, Cahill Jr F J. 2005. Plant phenotypic plasticity belowground: a phylogenetic perspective on root foraging trade-offs. The American Naturalist, 166(2): 216-230.

Khafagi A A F. 1995. The taxonomic significance of seed protein in some fabaceae species in Egypt. Annals of Agricultural Science, 40(1): $1-10$.

Li X Y, Zhang X M, Zeng F J, et al. 2002. Water relations on Alhagi sparsifolia in the southern fringe of Taklamakan Desert. Acta Botanica Sinica, 44(10): 1219-1224.

Li X Y, Lin L S, Zhao Q, et al. 2010. Influence of groundwater depth on species composition and community structure in the transition zone of Cele oasis. Journal of Arid Land, 2(4): 235-242.

Lloret F, Casanovas C, Penuelas J, et al. 1999. Seedling survival of Mediterranean shrubland species in relation to root: shoot ratio, seed size and water and nitrogen use. Functional Ecology, 13(2): 210-216.

Ma X D, Chen Y N, Zhu C G, et al. 2011. The variation in soil moisture and the appropriate groundwater table for desert riparian forest along the Lower Tarim River. Journal of Geographical Sciences, 21(1): 150-162.

Nilsson C, Jansson R, Zinko U. 1997. Long-term responses of river-margin vegetation to water-level regulation. Science, 276(5313): 798-800.

Pallardy S G, Rhoads J L. 1993. Morphological adaptations to drought in seedlings of deciduous angiosperms. Canadian Journal of Forest Research, 23(9): 1766-1774.

Pigliucci M. 2005. Evolution of phenotypic plasticity: where are we going now? Trends in Ecology \& Evolution, 20(9): 481-486.

Reader R J, Jalili A, Grime J P, et al. 1993. A comparative study of plasticity in seedling rooting depth in drying soil. Journal of Ecology, 81(3): 543-550.

Rood S B, Zanewich K, Stefura C, et al. 2000. Influence of water table 
decline on growth allocation and endogenous gibberellins in black cottonwood. Tree Physiology, 20(12): 831-836.

Schenk H J, Jackson R B. 2002. Rooting depths, lateral root spreads and below-ground/above-ground allometries of plants in water-limited ecosystems. Journal of Ecology, 90(3): 480-494.

Schenk H J. 2005. Vertical vegetation structure below ground: scaling from root to globe. In: Esser k, Lüttge U, Beyschlag W, et al. Progress in Botany. Heidelberg: Springer Berlin Heidelberg, 66: 341-373.

Schulze E D, Mooney H A, Sala O E, et al. 1996. Rooting depth, water availability, and vegetation cover along an aridity gradient in Patagonia. Oecologia, 108(3): 503-511.

Sharp R E, Davies W J. 1985. Root growth and water uptake by maize plant in drying soil. Journal of Experimental Botany, 36(9): 1441-1456.

Shaver G R, Billings W D. 1975. Root production and root turnover in a wet tundra ecosystem, Barrow, Alaska. Ecology, 56(2): 401-409.

Thomas F M, Arndt S K, Bruelheide H, et al. 2000. Ecological basis for a sustainable management of the indigenous vegetation in a central-Asian desert: presentation and first results. Journal of Applied Botany, 74(5-6): 212-219.

Via S, Gomulkiewicz R, De Jong G, et al. 1995. Adaptive phenotypic plasticity: consensus and controversy. Trends in Ecology \& Evolution, 10(5): 212-217.

Zhang K, Tian C Y, Li C J. 2012. Root growth and spatio-temporal distribution of three common annual halophytes in a saline desert, northern Xinjiang. Journal of Arid Land, 4(3): 330-341.

Zhou Z C, Shangguan Z P. 2007. Vertical distribution of fine roots in relation to soil factors in Pinus tabulaeformis Carr. forest of the Loess Plateau of China. Plant and Soil, 291(1-2): 119-129. 